\title{
Cooling performance of different dielectric fluids containing nanoparticles in a transformer winding
}

\author{
Agustín Santisteban \\ Electrical and Energy Engineering \\ Department \\ University of Cantabria \\ Santander, Spain \\ agustin.santisteban@unican.es \\ Fernando Delgado \\ Electrical and Energy Engineering \\ Department \\ University of Cantabria \\ Santander, Spain \\ fernando.delgado@unican.es
}

\author{
Cristian Olmo \\ Electrical and Energy Engineering \\ Department \\ University of Cantabria \\ Santander, Spain \\ cristian.olmo@unican.es \\ Carlos J. Renedo \\ Electrical and Energy Engineering \\ Department \\ University of Cantabria \\ Santander, Spain \\ renedoc@unican.es
}

\author{
Cristina Méndez \\ Electrical and Energy Engineering \\ Department \\ University of Cantabria \\ Santander, Spain \\ cristina.mendezgu@alumnos.unican.es \\ Félix Ortiz \\ Electrical and Energy Engineering \\ Department \\ University of Cantabria \\ Santander, Spain \\ felix.ortiz@unican.es
}

\begin{abstract}
This work presents a study where the thermal performance of different nanofluids is tested in a transformer winding model. A 2D non-isothermal CFD model has been used to compare temperature and velocity distribution of the proposed fluids. The fluids tested consists of eight different types coming from two different base fluids (mineral oil and natural ester), two different nanoparticles $\left(\mathrm{TiO}_{2}\right.$ and $\left.\mathrm{Fe}_{3} \mathrm{O}_{4}\right)$ and two different concentrations $(0.072 \% \mathrm{v}$ and $0.036 \% \mathrm{v})$. The comparison has been carried out between each fluid and their base fluid to observe the thermal impact of nanoparticles, thus ten cases were analyzed. The temperature dependent properties has been determined to include them in the simulation model. Two different inlet velocities were selected as inlet conditions, representing an Oil Natural Cooling $(0.0961 \mathrm{~m} / \mathrm{s})$ and an Oil Directed Cooling $(0.2451 \mathrm{~m} / \mathrm{s})$. The analysis has been carried out using ANSYS Fluent ${ }^{\circledR}$ with a $2 \mathrm{D}$ axisymmetric model. The fluids have been tested in a two pass winding model. The average and maximum disc temperatures and mass flow distributions are obtained for all the fluids tested. The results obtained show that the temperature in the seven discs of the considered winding increases when the nanoparticles are added to the natural ester, between 3 and $7 \%$. On the other hand, in the case of mineral oil, the addition of nanoparticles reduces the temperature in the discs between 0.3 and $3 \%$.
\end{abstract}

Keywords-nanofluids, thermal modelling, CFD, power transformer, natural ester.

\section{INTRODUCTION}

Power companies have been using power Transformers since the development of transmission and distribution networks. These electric machines are extremely robust and normally exceed 40 years of life. Most of them use mineral oil (a petroleum product) as dielectric and cooling fluid. The voltage levels of electric power transmission systems are increasingly high. This growth must be complemented by insulation systems with better dielectric capacities, with respect to conventional equipment [1]. In this way, a lot of research can be found in improving the dielectric properties of insulation, mainly paper and oil [2]. The fluids used in electric power transformers perform two main functions: to serve as electrical insulation between the different active parts of the machine, and to favor the evacuation of the heat generated. Typically highly refined oils are used, but they have a low thermal conductivity and therefore low cooling efficiency [3].
The advantages derived of nanoparticle addiction in the dielectric oil used by power transformers, have recently begun to be explored. In this line, the two most outstanding characteristics of these mixtures are: the improvement of the dielectric strength of the fluid and the increase in the cooling capacity of the electric machine, caused by the increase in thermal conductivity [4]. It has been shown that heat transfer in electromagnetic devices can be substantially improved by the use of magnetic fluids.

The addition of $\mathrm{Fe}_{3} \mathrm{O}_{4}$ nanoparticles to mineral oils can reduce the value of "hot spots" in transformer windings. The temperature of these points can be shortened up to $5^{\circ} \mathrm{C}$ [5]. In addition, the increase in cooling capacity may be associated with the decrease in the amount of oil needed [6]. Recent studies have shown that by adding $\mathrm{TiO}_{2}$ or $\mathrm{Fe}_{3} \mathrm{O}_{4}$ nanoparticles in transformer oil, it acquires better electrical insulation properties and greater resistance to the thermal aging caused by moisture [7-8].

With respect to the previous scientific works that have studied the refrigeration of transformers with nanofluids, recent works are mentioned below.

In 2003, Snyder et al. carried out a first numerical simulation in which they studied the magnetoconvection of a ferrofluid inside a cube, in the presence of a magnetic field gradient and a temperature gradient [9]. Six years later, in 2009, Lee and Kim studied the effect produced by an alternating magnetic field on the cooling capacity of a magnetofluid [10].

A more complex numerical study [11] appeared 10 years after the publication of the first study, May 2013. The authors proposed a thermo-fluid-magnetic model in order to compare the cooling efficiency in a winding with a nanofluid, a transformer oil and air. The validation of the numerical results of this last study was carried out through a real platform that replicated experimentally the numerical study.

In June 2013, Pislaru-Danescu et al. carried out a much more comprehensive theoretical-practical study, in which they compare the temperature measurements in a ferrofluid consisting of a colloidal dispersion of magnetite particles in a mineral oil- with those measured in mineral oil. For this comparison the authors proposed two approaches: first, by means of a numerical thermofluid-magnetic analysis of 
several 2D and 3D models of a small single-phase transformer $(36 \mathrm{kV}, 40 \mathrm{kVA})$; and second, by calculating the temperatures from the heating test performed on singlephase transformer mentioned [12]. A study derived from this last article is the one published by the same authors in November of 2013 [13].

Finally, February 2014, Weimin Guan et al [14] published an article analyzing the influence of the local density of nanoparticles and electrophoresis on the distribution of temperatures and refrigerant speeds. To do this, they simulated a 2D model of a single-phase, low-power transformer using a thermo-fluid-electric numerical model.

This research will seek to expand current knowledge about the application of dielectric nanofluids to power transformers. This paper includes activities related to the production-characterization of these fluids and their performance in the cooling ducts of windings. Thus, the study will assess the suitability of using nanoparticles in transformer dielectric oil, using these results to quantify the influence of the nanofluids in the geometrical design of the transformers.

\section{EXPERIMENTAL SETUP}

The base liquids used to produce the studied nanofluids were two commercial dielectric oils, a mineral oil and a natural ester, Table I. The used nanoparticles were also commercially available. The $\mathrm{TiO}_{2}$ was characterized by Transmission Electron Microscopy, using a JEOL JEM 2100 equipment operating at 120 kV. Fig. 1 shows the morphological characterization of $\mathrm{TiO}_{2}$ nanoparticles, and Table II lists the properties of this type of nanoparticles. The other nanoparticle used was magnetite $\left(\mathrm{Fe}_{3} \mathrm{O}_{4}\right)$, which has been supplied in the form of a colloidal dispersion (ferrofluid). Its most representative properties are shown in Table III.

TABLE I. SPECIFICATIONS OF OILS USED FOR THE NANOFLUIDS

\begin{tabular}{|l|c|c|}
\hline \multicolumn{1}{|c|}{ Property } & Mineral oil & Natural ester \\
\hline Breakdown voltage $(\mathrm{kV})$ & 30 & $>75$ \\
\hline Kinematic Ciscosity at $40^{\circ} \mathrm{C}\left(\mathrm{mm}^{2} / \mathrm{s}\right)$ & 10.3 & 39.2 \\
\hline Density at $20^{\circ} \mathrm{C}\left(\mathrm{g} / \mathrm{cm}^{3}\right)$ & 0.84 & 0.91 \\
\hline Pour point $\left({ }^{\circ} \mathrm{C}\right)$ & -48 & -25 \\
\hline
\end{tabular}

TABLE II. SPECIFICATIONS OF $\mathrm{TIO}_{2}$ NANOPARTICLES

\begin{tabular}{|l|c|}
\hline \multicolumn{1}{|c|}{ Property } & Specification \\
\hline Density $\left(\mathrm{g} / \mathrm{cm}^{3}\right)$ & 3.89 \\
\hline Morphology & Spherical \\
\hline Specific Surface Area $\left(\mathrm{m}^{2} / \mathrm{g}\right)$ & $>120$ \\
\hline Purity (\%) & 99.5 \\
\hline Average diameter $(\mathrm{nm})$ & 80 \\
\hline
\end{tabular}

Identify applicable funding agency here. If none, delete this text box.

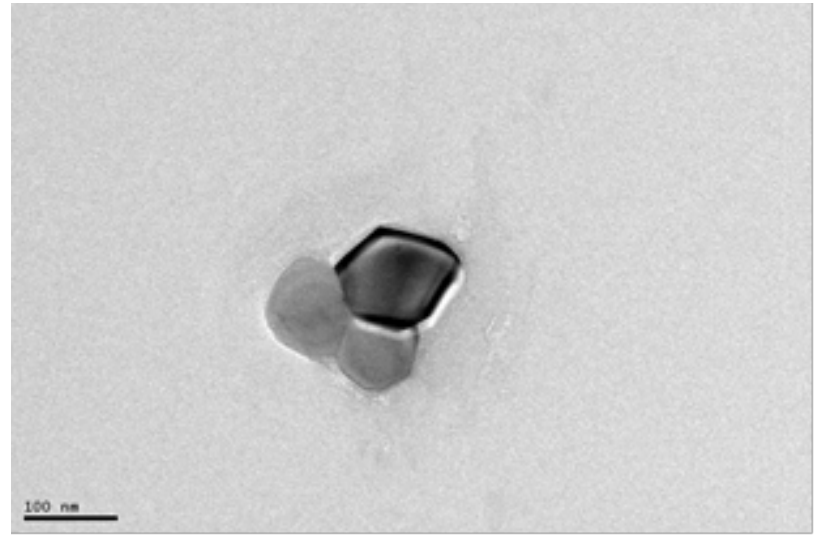

Fig. 1. Morphological characterization of $\mathrm{TiO}_{2}$ nanoparticles

TABLE III. SPECIFICATIONS OF FERROFLUID $\left(\mathrm{FE}_{3} \mathrm{O}_{4}\right)$

\begin{tabular}{|l|c|}
\hline \multicolumn{1}{|c|}{ Property } & Specification \\
\hline Density $\left(\mathrm{g} / \mathrm{cm}^{3}\right)$ & $0.92-1.47$ \\
\hline Content of magnetite nanoparticles (\%v) & $3-15$ \\
\hline Boiling point $\left({ }^{\circ} \mathrm{C}\right)$ & $205-255$ \\
\hline Solubility in water & Negligible \\
\hline Oil soluble dispersant content (\%v) & $6-30$ \\
\hline Content of carrier fluid (\%v) & $55-91$ \\
\hline
\end{tabular}

TABLE IV. STUDIED NANOFLUIDS

\begin{tabular}{|c|c|c|c|}
\hline Code & Oil & Nanoparticle & Concentration \\
\hline A & Mineral & $\mathrm{TiO}_{2}$ & $0.072 \% \mathrm{v}$ \\
\hline C & Mineral & $\mathrm{TiO}_{2}$ & $0.036 \% \mathrm{v}$ \\
\hline E & Mineral & $\mathrm{Fe}_{3} \mathrm{O}_{4}$ & $0.072 \% \mathrm{v}$ \\
\hline G & Mineral & $\mathrm{Fe}_{3} \mathrm{O}_{4}$ & $0.036 \% \mathrm{v}$ \\
\hline $\mathrm{B}$ & Ester & $\mathrm{TiO}_{2}$ & $0.072 \% \mathrm{v}$ \\
\hline $\mathrm{D}$ & Ester & $\mathrm{TiO}_{2}$ & $0.036 \% \mathrm{v}$ \\
\hline $\mathrm{F}$ & Ester & $\mathrm{Fe}_{3} \mathrm{O}_{4}$ & $0.072 \% \mathrm{v}$ \\
\hline $\mathrm{H}$ & Ester & $\mathrm{Fe}_{3} \mathrm{O}_{4}$ & $0.036 \% \mathrm{v}$ \\
\hline
\end{tabular}

Oil-based nanofluids were prepared by dispersing nanoparticles on base oil. The dispersion was carried out uniform through an ultrasonic bath (Elmasonic P300H) at 37 $\mathrm{kHz}$ and for 12 hours. For each fluid, two different concentrations of nanoparticles have been used, $0.036 \% \mathrm{v}$ and $0.072 \% \mathrm{v}$. The nanoparticle concentration and the nanoparticles used to obtain the studied nanofluids are gathered in Table IV.

\section{COMPUTATIONAL FLUID DYNAMICS ANALYSIS}

Nanoparticle addition to dielectric liquids has some benefits, such as a raise on the breakdown voltage. However, the thermal behavior of nanofluids in transformer windings is not deeply tested. In this work, the cooling performance of dielectric nanofluids in a transformer winding is studied. To assess this property, a CFD study has been carried out. 
This task is performed by doing a 2D non-isothermal CFD model of a part of a power transformer disc-type winding. The CFD analysis provides information of the oil velocities and winding temperatures, especially the hot spot temperature. The hot spot temperature is considered for the assessment of the cooling performance of the nanofluids.

The numerical model is based on the differential equations that governs the fluid flow and heat transfer. These are the Navier-Stokes and energy equations for incompressible fluids in a steady state regime (See Eqs. (1)- (3)).

$$
\begin{gathered}
\nabla \cdot(\rho U)=0 \\
\nabla \cdot(\rho U \times U)=-\nabla p+\mu\left(\nabla^{2} U\right)+g \cdot\left(\rho-\rho_{0}\right) \\
\nabla \cdot\left(\rho c_{p} U T\right)=\nabla \cdot(k \nabla T)+S_{E}
\end{gathered}
$$

Where the term $\rho$ represents the density, $\mu$ the viscosity, $U$ the velocity, $\mathrm{p}$ the pressure, $\mathrm{g}$ the gravity, $\mathrm{T}$ the temperature, $\mathrm{c}_{\mathrm{p}}$ the specific heat and $\mathrm{k}$ the thermal conductivity.

The geometry represents a part of a power transformer disc-type winding. Consists of 16 discs separates in two passes by $2 \mathrm{~mm}$ high oil guiders (or washers). The upstream pass contains 9 discs and the downstream pass contains 7 discs. The discs are separated by spacer of $5 \mathrm{~mm}$ height, and between disc and washers are placed 3mm high spacers. Between discs and both internal and external insulation cylinder are placed sticks of $6 \mathrm{~mm}$ width. Fig. 2 represents the winding considered in this work. The results of the analysis will be taken from the downstream pass; the upstream pass is modelled to mitigate the effect of uniform profiles of velocity and temperature at the inlet.

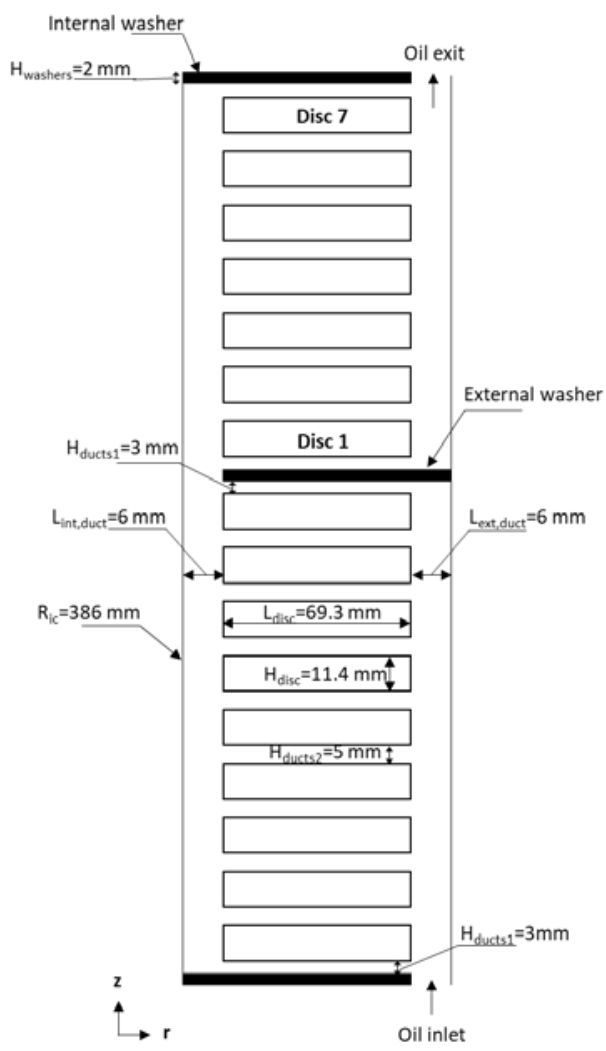

Fig. 2. Disc-type winding geometry with dimensions

Specifications of oils used for the nanofluids

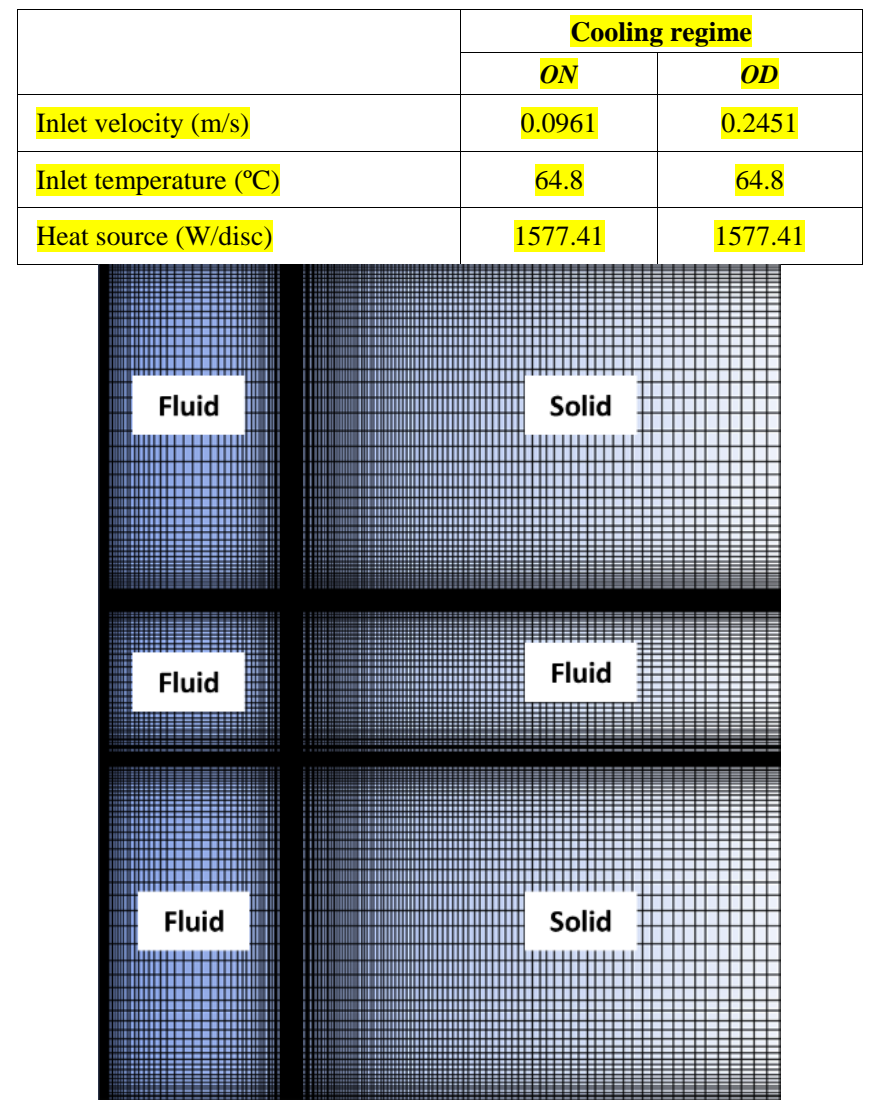

Fig. 3. Numerical mesh of the CFD model

For the study, two different inlet velocities are considered for all fluids, representing a typical velocity from an $\mathrm{ON}$ and an OD regime. Also, the inlet temperature and the heat source of the winding discs are considered. Table $\mathrm{V}$ represents the boundary conditions for these two different cases. Since the Reynolds number does not exceed 500, the flow is assumed laminar. In addition, the thermal conductivity of the discs is reduced to an equivalent axial and radial thermal conductivity, whose values are 3.751 and $0.646 \mathrm{~W} /(\mathrm{m} \cdot \mathrm{K})$ respectively.

For the CFD analysis, the model was created with ANSYS software. A quadrilateral mesh of about 700,000 elements was generated with ANSYS meshing and the equations were solved with ANSYS Fluent. The convergence criteria was set that the residuals were below 1e-6. Fig. 3 shows the mesh for the analysis.

\section{RESULTS AND DISCUSSION}

In this section, the results from the analysis will be presented and discussed.

\section{A. ON case}

\section{1) Mineral oil-based fluids}

For mineral oil-based nanofluids, their thermal behavior is slightly better than the base fluid, except for the fluid A, whose thermal behavior is worse. Average and maximum disc temperatures predicted for nanofluids $\mathrm{C}, \mathrm{E}$ and $\mathrm{G}$ are lower than the base fluid. Fig. 4 presents the maximum disc temperatures, where can be appreciated that for the fluid A, the temperatures are higher than the rest of fluids. Table VI summarizes the results from this part of the study, showing the average winding temperature, the hot spot temperature and its location, where can be observed that the nanofluids, 
except for the fluid A, decreases the hot spot temperature of the base fluid between $0.2-1.4{ }^{\circ} \mathrm{C}$.

\section{2) Natural ester-based fluids}

In the case of natural ester-based nanofluids, the behavior is different from mineral oil-based nanofluids. In this case, the average and maximum disc temperatures predicted for the nanofluids considered are higher than the base fluid. Fig. 5 shows the maximum disc temperature in this case, where can be observed that the lowest temperatures predicted were for the base fluid, between 3.4-7.1 ${ }^{\circ} \mathrm{C}$ lower than the nanofluids considered. Table VII presents the results from this study.

TABLE V. RESULTS FROM THE ON CASE WITH MINERAL OIL-BASED NANOFLUIDS

\begin{tabular}{|l|c|c|c|}
\hline \multicolumn{1}{|c|}{ Fluid } & Tw ( $\left.{ }^{\mathbf{0}} \mathbf{C}\right)$ & Th $\left({ }^{\circ} \mathbf{C}\right)$ & HSL \\
\hline Base fluid & 94.4 & 105.3 & Disc 2 \\
\hline A & 95.7 & 107.8 & Disc 4 \\
\hline C & 92.9 & 103.9 & Disc 2 \\
\hline E & 93.8 & 105.1 & Disc 2 \\
\hline G & 92.7 & 104.7 & Disc 2 \\
\hline
\end{tabular}

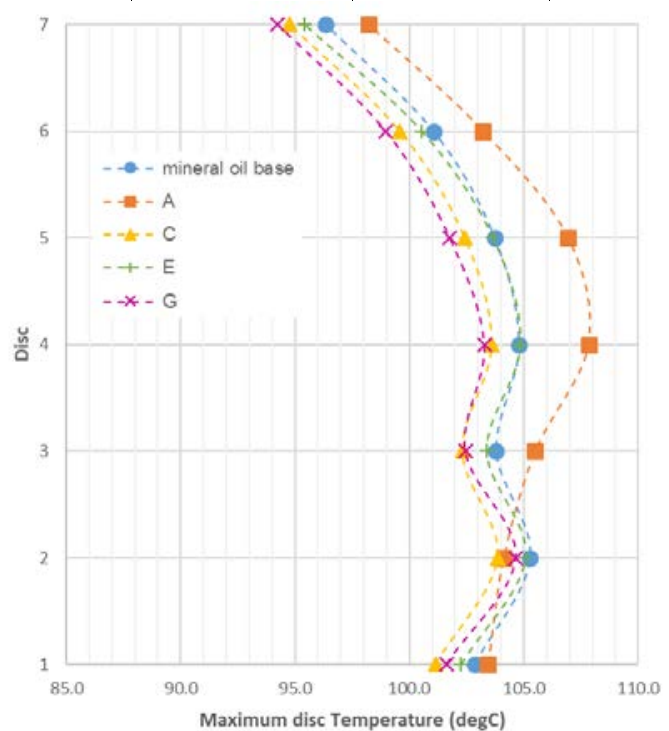

Fig. 4. Maximum disc temperature for the mineral oil-based fluids.

TABLE VI. RESULTS FROM THE ON CASE WITH NATURAL ESTER-BASED NANOFLUIDS

\begin{tabular}{|l|c|c|c|}
\hline \multicolumn{1}{|c|}{ Fluid } & Tw $\left({ }^{\mathbf{0}} \mathbf{C}\right)$ & Th $\left({ }^{\circ} \mathbf{C}\right)$ & HSL \\
\hline Base fluid & 86.6 & 95.8 & Disc 4 \\
\hline B & 89.4 & $99 . .2$ & Disc 4 \\
\hline D & 92.2 & 102.9 & Disc 4 \\
\hline F & 92.1 & 102.6 & Disc 4 \\
\hline H & 89.9 & 99.9 & Disc 4 \\
\hline
\end{tabular}

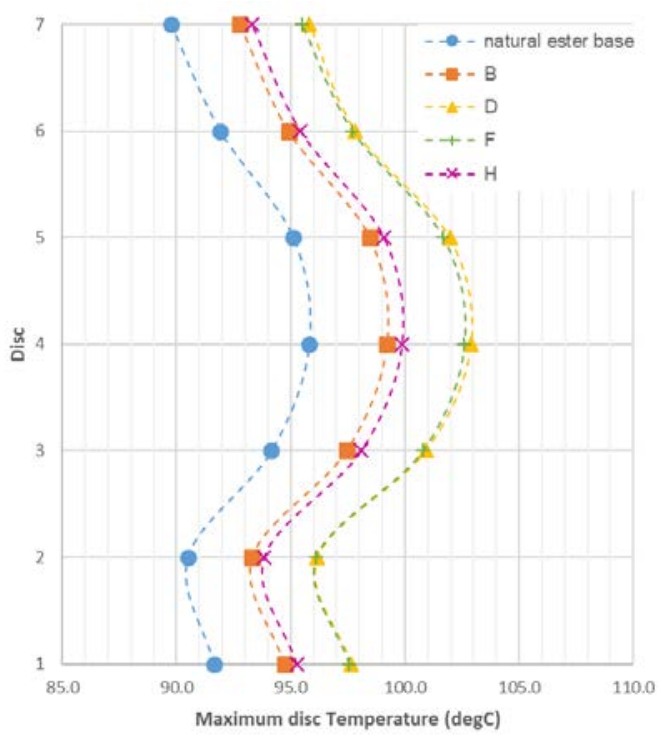

Fig. 5. Maximum disc temperature for the natural ester-based fluids.

\section{B. OD case}

\section{1) Mineral oil-based fluids}

For the OD case, the hot spot temperature is located in the first disc of the pass, due to a flow maldistribution where the mass flow fraction through the first radial channel is below $0.7 \%$, except for the fluid A where the hot spot is located in the third disc. This effect is appreciated in the maximum disc temperature distribution displayed in Fig. 6. The hot spot temperatures are similar to the ON case, except for fluid A that presents the lowest hot spot temperature. Table VIII presents the results from this study. It can be observed that the hot spot temperature decreased with the addition of nanoparticles with respect to the base case, except for the sample G.

\section{2) Natural ester-based fluids}

In the case of natural ester-based fluids, the average and maximum disc temperatures are higher than the base fluid. The temperatures predicted are lower than in the ON case. Table IX presents the average winding and the hot spot temperature for this study. In this case, as well as in the ON case, the hot spot temperature increases with the addition of nanoparticles.

TABLE VII. RESULTS FROM THE OD CASE WITH MINERAL OIL-BASED NANOFLUIDS

\begin{tabular}{|l|c|c|c|}
\hline \multicolumn{1}{|c|}{ Fluid } & $\mathbf{T w}\left({ }^{\circ} \mathbf{C}\right)$ & Th $\left({ }^{\circ} \mathbf{C}\right)$ & HSL \\
\hline Base fluid & 87.2 & 105.4 & Disc 1 \\
\hline A & 87.2 & 99.2 & Disc 3 \\
\hline C & 86.2 & 101.5 & Disc 1 \\
\hline E & 86.8 & 103.8 & Disc 1 \\
\hline G & 86.7 & 106.7 & Disc 1 \\
\hline
\end{tabular}




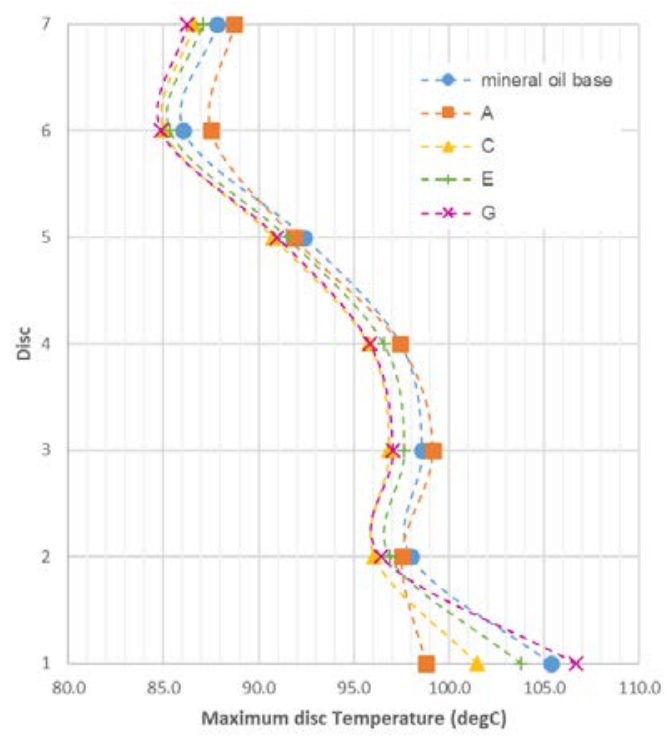

Fig. 6. Maximum disc temperature for the mineral oil-based fluids.

TABLE VIII. RESULTS FROM THE OD CASE WITH NATURAL ESTER-BASED NANOFLUIDS

\begin{tabular}{|l|c|c|c|}
\hline \multicolumn{1}{|c|}{ Fluid } & Tw $\left({ }^{\circ} \mathbf{C}\right)$ & Th $\left({ }^{\circ} \mathbf{C}\right)$ & HSL \\
\hline Base fluid & 80.1 & 86.8 & Disc 2 \\
\hline B & 81.7 & 88.3 & Disc 4 \\
\hline D & 83.1 & 90.5 & Disc 4 \\
\hline F & 83.2 & 90.4 & Disc 2 \\
\hline H & 81.9 & 88.7 & Disc 2 \\
\hline
\end{tabular}

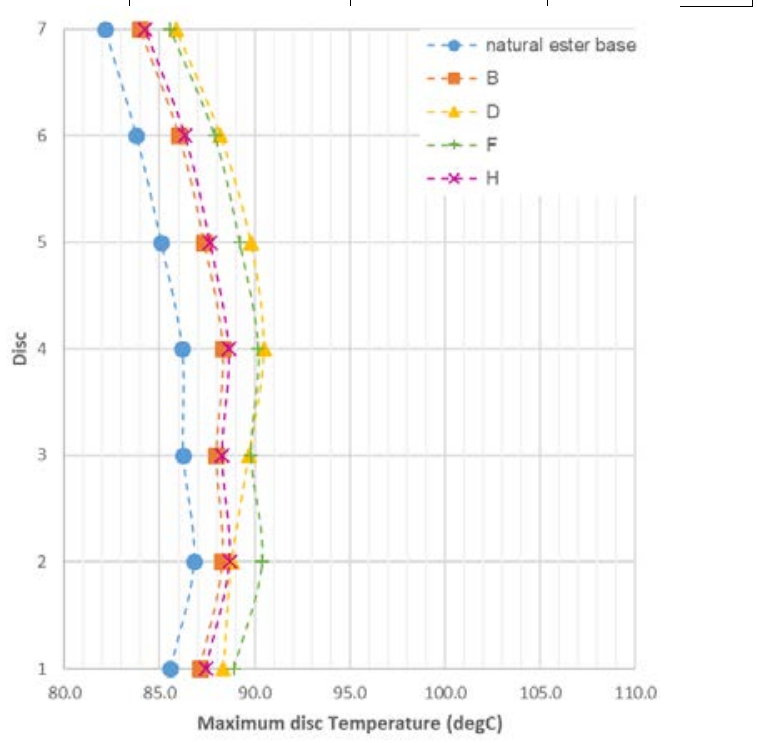

Fig. 7. Maximum disc temperature for the natural ester-based fluids.

\section{CONCLUSIONS}

From the results obtained in this study, the addition of nanoparticles to the dielectric liquids has controversial results. With mineral oil, the proposed nanofluids seem to have a similar, slightly better thermal behavior than the base fluid, except for one sample. This exception has two different behaviors compared with the rest of fluids. In the ON case, its thermal behavior is worse, leading to a higher hot spot temperature, probably due to a higher viscosity of the sample.
In the OD case, this sample presents the lowest hot spot temperature due to a maldistribution of the mass flow through radial channels appearing in the rest of fluids. For this sample, the higher viscosity and the higher Reynolds number leads to a lower effect on this maldistribution and a lower hot spot temperature than the rest of fluids.

In the case of natural ester-based fluids, the thermal performance is in the opposite way than with mineral oil. For the proposed nanofluids, the hot spot temperature is higher than the obtained with base fluid. In this case, with a more viscous base fluid, the thermal effect of nanoparticles is the opposite than with mineral oil, the increase of the thermal conductivity has a lower impact, leading to higher hot spot temperatures due to the increase of the viscosity.

\section{ACKNOWLEDGMENT}

The authors of this research wish to thank the Ministry of Economy for financial support to the National Research Project: Improvement of Insulation Systems of Transformers through Dielectric Nanofluids (DPI2015-71219-C2 1-R).

\section{REFERENCES}

[1] K. Karsai, D. Kerenyi, and L. Kiss, Large Power Transformers, Amsterdam, The Netherlands: Elsevier, 1987, pp. 351-359.

[2] R. J. Liao, J. Hao, L. J. Yang, S. W. Liang, and J. G. Yin, “Improvement on the anti-aging properties of power transformers by using mixed insulating oil,” in 2010 Int. Conf. High Voltage Engineering and Application (ICHVE), pp. 588-591.

[3] H. G. Erdman, “Electrical Insulating Oils STP 998”, ASTM Publ. Co. Philadelphia, 1996.

[4] M. Chiesa and S. K. Das, "Experimental investigation of the dielectric and cooling performance of colloidal suspensions," Insul. Media. Colloids Surf. A, vol. 335, no. 1-3, pp. 88-97, 2009.

[5] G. Y. Jeong, S. P. Jang, H. Y. Lee, J. C. Lee, S. Choi, and S. H. Lee, "Magnetic-thermalfluidic analysis for cooling performance of magnetic nanofluids comparing with transformer oil and air by using fully coupled finite element method,” IEEE Trans. Magn., vol. 49, no. 5, pp. 1865-1868, 2013.

[6] L. P. Danescu, A. M. Morega, M. Morega, V. Stoica, O. M. Marinica, F. Nouras, N. Paduraru, I. Borbath, and T. Borbath, "Prototyping a ferrofluidcooled transformer,” IEEE Trans. Ind. Appl., vol. 49, no. 3, pp. 1289-1298, 2013.

[7] Y. F. Du, Y. Z. Lv, C. R. Li, M. T. Chen, J. Q. Zhou, X. X. Li, Y. Zhou, and Y.X. Zhong, "Effect of electron shallow trap on breakdown performance of transformer oil-based nanofluids,”J. Appl. Phys., vol. 110, no. 10, art. no. 104104, 2011.

[8] Y. Z. Lv, Y. F. Du, C. R. Li, B. Qi, Y. Zhong, and M. Chen, “TiO2 nanoparticle induced space charge decay in thermal aged transformer oil," Appl. Phys. Lett., vol. 102, no. 13, art. no. 132902, 2013.

[9] Snyder, Suzanne M., Tahir Cader, and Bruce A. Finlayson. "Finite Element Model of Magnetoconvection of a Ferrofluid." Journal of Magnetism and Magnetic Materials 262 (2): 269-279, 2003.

[10] Lee, Se-Hee. "Finite Element Analysis for Cooling Effect of Magnetic Fluid with Alternating Magnetic Field." Journal of Applied Physics 105 (7), 2009.

[11] Jeong, Geun-Young. "Magnetic-Thermal-Fluidic Analysis for Cooling Performance of Magnetic Nanofluids Comparing with Transformer Oil and Air by using Fully Coupled Finite Element Method." IEEE Transactions on Magnetics 49 (5): 1865-1868, 2013.

[12] Pîslaru-Danescu, L., A. M. Morega, M. Morega, V. Stoica, O. M. Marinica, F. Nouras, N. Paduraru, I. Borbath, and T. Borbath. "Prototyping a Ferrofluid-Cooled Transformer." IEEE Transactions on Industry Applications 49 (3): 1289-1298, 2013.

[13] Pislaru-Danescu, L., A. M. Morega, G. Telipan, M. Morega, J. B. Dumitru, and V. Marinescu. "Magnetic Nanofluid Applications in Electrical Engineering." IEEE Transactions on Magnetics 49 (11): 5489-5497, 2013.

[14] Guan, Weimin. "Finite Element Modeling of Heat Transfer in a Nanofluid Filled Transformer." IEEE Transactions on Magnetics 50 (2): 253-256; 2014.

[15] F. Torriano, P. Picher, M. Chaaban, "Numerical investigation of 3D flow and thermal effects in a disc-type transformer winding”, in Applied Thermal Engineering (2012), Vol. 40, pp. 121-131. 